Research Paper

\title{
R.E.N.A.L. Nephrometry Score: A Preoperative Risk Factor Predicting the Fuhrman Grade of Clear-Cell Renal Carcinoma
}

\author{
Shao-Hao Chen*, Yu-Peng Wu*, Xiao-Dong Li", Tian Lin, Qing-Yong Guo, Ye-Hui Chen, Jin-Bei Huang, \\ Yong Wei, Xue-Yi Xue, Qing-Shui Zheng ${ }^{\bowtie}$, Ning $\mathrm{Xu}^{\bowtie}$ \\ Department of Urology, First Affiliated Hospital of Fujian Medical University, Fuzhou 350005, China \\ * These three authors contributed equally to this work. \\ $\square$ Corresponding author: Qing-Shui Zheng and Ning Xu, Department of Urology, the First Affiliated Hospital of Fujian Medical University, 20 Chazhong Road, \\ Fuzhou 350005, China. Tel.: +86-059187981687; E-mail address: zhengqingshui@fjmu.edu.cn (Qing-Shui Zheng) drxun@fjmu.edu.cn (Ning Xu) \\ ( ) Ivyspring International Publisher. This is an open access article distributed under the terms of the Creative Commons Attribution (CC BY-NC) license \\ (https://creativecommons.org/licenses/by-nc/4.0/). See http://ivyspring.com/terms for full terms and conditions.
}

Received: 2017.05.26; Accepted: 2017.08.19; Published: 2017.10.17

\begin{abstract}
Objective: The purpose of this study was to evaluate the efficacy and feasibility of the R.E.N.A.L. Nephrometry Score to postoperatively predict high-grade clear-cell renal carcinoma (ccRCC).

Methods: The study included 288 patients diagnosed with ccRCC who had complete CT/CTA data and R.E.N.A.L. Nephrometry Scores and underwent renal surgery at our center between January 2012 and December 2015. The relationship between the pathological grade of renal masses and R.E.N.A.L. Nephrometry Score was evaluated.

Results: Univariate analysis indicated that diagnostic modality, cystic necrosis, enlargement of the regional lymph node, distant metastasis, clinical T stage, TNM stage, surgical modality, tumor size, nearness of the tumor to the collecting system or sinus, total Nephrometry Score and individual anatomic descriptor components were significantly associated with postoperative tumor grade $(P$ $<0.05$ ). Multivariate analysis showed that tumor size, the maximal diameter ( $\mathrm{R}$ score), exophytic/endophytic properties (E score) and the location relative to the polar lines ( $L$ score) were independent prognostic factors to preoperatively predicting $c c R C C$ pathological grade. The areas under the ROC curve with respect to the multi-parameter regression model $(0.935,95 \% \mathrm{Cl}$ : $0.904-0.966)$, tumor size $(0.901,95 \% \mathrm{Cl}: 0.866-0.937), \mathrm{R}$ score $(0.868,95 \% \mathrm{Cl}: 0.825-0.911)$, E score $(0.511,95 \% \mathrm{Cl}: 0.442-0.581)$ and $\mathrm{L}$ score $(0.842,95 \% \mathrm{Cl}: 0.791-0.892)$ were calculated and compared.

Conclusion: Tumor size, as well as $R, E$, and $L$ scores were independent prognostic factors for high-grade pathology. Lager tumor sizes and higher R, E and $L$ scores were more likely to be associated with high-grade pathological outcomes. Thus, the R.E.N.A.L. Score is of practical significance in facilitating urologists to make therapeutic decisions.
\end{abstract}

Key words: Clear-cell renal carcinoma, fuhrman grade, the R.E.N.A.L score, predicting.

\section{Introduction}

Fuhrman grades are the most commonly used histologic grade for renal carcinoma [1]. For patients with clear-cell renal cell carcinoma (ccRCC), Fuhrman grades of I-II are associated with better prognosis, and nephron sparing surgery can be performed safely and with minimal morbidity in these patients.
However, ccRCC patients with Fuhrman grades of III-IV are associated with poor prognosis and high morbidity [2, 3]. Scosyrev et al. reported that nephron-sparing surgery was correlated with reduced overall survival (OS) compared with radical nephrectomy $(\mathrm{RN})$ (hazard ratio: $1.50 ; 95 \%$ confidence 
interval (CI), 1.03-2.16) [4]. Patients with higher ccRCC stages who underwent partial nephrectomy $(\mathrm{PN})$ were associated with worse clinicopathological outcomes [5]. Van et al. also reported that PN seems to be significantly less effective than RN with respect to OS [6]. Meanwhile, Leibovich et al. reported that patients who underwent RN were less likely to have recurrence compared with those underwent PN [7]. Additionally, Larcher et al. showed that PN did not improve other-cause survival relative to $\mathrm{RN}$ consistently in all renal carcinoma patients [8]. Fuhrman grade III-IV is treated as an independent predictor of late recurrence 5 years after surgery in RCC patients [9]. Thus, PN use should be more selective, and Fuhrman grade should be considered by urologists when making therapeutic decisions [10]. For the sake of good therapeutic efficacy, it is of grave importance and practical significance to accurately predict the pathological stage of renal masses upon diagnosis.

The standardized nephrometry scoring system, R.E.N.A.L. Nephrometry Score, was established by Alexander et al. to quantify the anatomical characteristics of renal masses on computerized tomography $(\mathrm{CT}) /$ magnetic resonance imaging and is widely used around the world [11]. The purpose of this study was to explore the relationship between the pathological grade of renal masses and the R.E.N.A.L. Nephrometry Score. The practical significance of R.E.N.A.L. Nephrometry Score in predicting pathological grade of renal masses was further evaluated.

\section{Materials and Methods}

\section{Study population}

Our study was approved by the Ethical Committee and Institutional Review Board of the First Affiliated Hospital of Fujian Medical University. This study enrolled 288 ccRCC patients with complete CT/CTA data who underwent renal surgery at our center between January 2012 and December 2015. Renal surgery consisted of nephron sparing surgery and RN. Only unilateral, unifocal, and pathologically confirmed ccRCCs were included. Unilateral multifocal tumors, bilateral multifocal tumors, cystic renal tumors, local or distant metastasis tumors and polycystic kidney disease were excluded. Additionally, patients who underwent biopsy of renal masses prior to surgery were also excluded. Patients with ccRCC that was discovered by physical examination were considered the asymptomatic group. Patients with hematuria, flank pain or abdominal masses were classified as the symptomatic group. RCC stage was assigned by surgical pathology based on the American Joint Committee on Cancer (AJCC) 2010 TNM classification. Fuhrman grade I and II were classified as low Fuhrman grade (LFG), and Fuhrman grade III and IV were classified as high Fuhrman grade (HFG) [3, 12].

\section{Statistical analysis}

Radiographic features of the renal masses were evaluated and scored using the R.E.N.A.L. Nephrometry Score. Each component of Nephrometry was compared with the histology and grade of resected renal masses to validate whether radiographic features of renal masses could predict renal tumor pathology [12]. Imaging characteristics of all cases were evaluated by two residents at our center using the R.E.N.A.L scoring system. Disagreements were resolved by a third attending urologist. Demographic features, radiographic characteristics of the renal masses prior to surgery, surgical modalities, clinical and pathological stage, total Nephrometry Score and individual anatomic descriptor components were also summarized. The relationship between pathological grade and clinicopathological characteristics mentioned above were evaluated. Statistical analysis was conducted using SPSS 18.0 (SPSS Inc., Chicago, IL, USA). The chi-square test was used to compare qualitative variables; other comparisons were made using appropriate statistical tests. Student's $\mathrm{t}$ test was performed to compare continuous variables. Multivariable logistic regression was performed to determine predictors of the postoperative pathological grade of renal masses, and receiver operating characteristic curves (ROC) were further constructed. $\mathrm{P}<0.05$ was considered statistically significant for all tests [13].

\section{Results}

The demographic, clinical, and pathological information of all cases are presented in Table 1. Total Nephrometry Score and individual anatomic descriptor components of ccRCC are presented in Figure 1 and Figure 2. Diagnostic modality, tumor size, nearness of the tumor to the collecting system or sinus, CT that showed cystic necrosis, CT that showed enlargement of regional lymph node, distant metastasis, surgical modality, total Nephrometry Score and individual anatomic descriptor components significantly differed between the HFG and LFG groups (Tables 1 and 2; $\mathrm{P}<0.05$ ). Further multivariable logistic regression demonstrated that maximal diameter (R), exophytic/endophytic properties (E), and the location relative to the polar lines (L) were significantly associated with preoperative ccRCC pathological grade (Table 3). R was significantly correlated with the HFG group, 
tumors with R scores of 2 points showed 11.59-fold higher risk for HFG postoperatively than those with $\mathrm{R}$ scores of 1 point. Additionally, R scores of 3 points showed 17.56-fold higher risk for HFG postoperatively than those with $\mathrm{R}$ scores of 2 points. E scores of 2 points showed 5.10-fold higher risk for
HFG postoperatively than those with E scores of 1 point. L scores of 3 points showed 26.85-fold higher risk for HFG postoperatively than those with L scores of 1 point (Table $4 ; \mathrm{P}<0.05$ ).

Table 1. Comparison of clinicopathological characteristics of cases with different fuhrman grade.

\begin{tabular}{|c|c|c|c|c|}
\hline & LFG & HFG & P value & Total \\
\hline Cases, $\mathrm{n}$ & 197 & 91 & & 288 \\
\hline Age, year & $43.6 \pm 11.7(18-65)$ & $52.7 \pm 12.0(18-81)$ & 0.159 & $55.5 \pm 12.36(18-85)$ \\
\hline Tumor size $^{1}, \mathrm{~cm}$ & $4.07 \pm 1.86(0.8-13.0)$ & $7.89 \pm 2.5(3.0-17.0)$ & $<0.001^{*}$ & $5.276 \pm 2.759(0.8-17.0)$ \\
\hline Nearness ${ }^{1,2}, \mathrm{~mm}$ & $5.23 \pm 6.02(0-36.0)$ & $1.89 \pm 7.08(0-61.4)$ & $<0.001^{*}$ & $4.173 \pm 6.547(0-61.4)$ \\
\hline Gender, n (\%) & & & 0.552 & \\
\hline Male & $141(71.6 \%)$ & $62(68.1 \%)$ & & $203(70.5)$ \\
\hline Female & $56(28.4 \%)$ & $29(31.9 \%)$ & & $85(29.5)$ \\
\hline Tumor location, $\mathrm{n}(\%)$ & & & 0.899 & \\
\hline Left kidney & $99(50.3 \%)$ & $47(51.6 \%)$ & & $146(50.7)$ \\
\hline Right kidney & $98(49.7 \%)$ & $44(48.4 \%)$ & & $142(49.3)$ \\
\hline Diagnostic modality, n (\%) & & & $<0.001^{*}$ & \\
\hline Physical examination & $141(71.6 \%)$ & $42(46.2 \%)$ & & $183(63.5)$ \\
\hline Symptom & $56(28.4 \%)$ & $49(53.8 \%)$ & & $105(36.5)$ \\
\hline Hypertension, $\mathrm{n}(\%)$ & & & 1 & \\
\hline No & $131(66.5 \%)$ & $60(65.9 \%)$ & & $191(66.3)$ \\
\hline Yes & $66(33.5 \%)$ & $31(34.1 \%)$ & & $97(33.7)$ \\
\hline Diabetes, n (\%) & & & 0.414 & \\
\hline No & $178(90.4 \%)$ & $79(86.8 \%)$ & & $257(89.2)$ \\
\hline Yes & $19(9.6 \%)$ & $12(13.2 \%)$ & & $31(10.8)$ \\
\hline Smoking history, $\mathrm{n}(\%)$ & & & 0.224 & \\
\hline No & $138(70.1 \%)$ & $57(62.6 \%)$ & & $195(67.8)$ \\
\hline Yes & $57(28.9 \%)$ & $34(37.4 \%)$ & & $93(32.2)$ \\
\hline $\begin{array}{l}\text { Preoperative lymphocyte count } \\
<1.1^{*} 109 / \mathrm{L}, \mathrm{n}(\%)\end{array}$ & & & 0.664 & \\
\hline No & $178(90.4 \%)$ & $84(92.3 \%)$ & & $262(91.0)$ \\
\hline Yes & $19(9.6 \%)$ & $17(18.7 \%)$ & & $26(9.0)$ \\
\hline $\mathrm{CT}$ showed cystic necrosis, $\mathrm{n}(\%)$ & & & $0.01^{*}$ & \\
\hline No & $126(64.0 \%)$ & $43(47.3 \%)$ & & $169(58.7)$ \\
\hline Yes & $71(36.0 \%)$ & $48(52.7 \%)$ & & $119(41.3)$ \\
\hline CT showed ERLN, n (\%) & & & $0.002^{*}$ & \\
\hline No & $191(97.0 \%)$ & $79(86.8 \%)$ & & $270(93.8)$ \\
\hline Yes & $6(3.0 \%)$ & $12(13.2 \%)$ & & $18(6.2)$ \\
\hline Distant metastasis, $\mathrm{n}(\%)$ & & & $<0.001^{*}$ & \\
\hline No & $197(100 \%)$ & $84(92.3 \%)$ & & $281(97.6)$ \\
\hline Yes & $0(0 \%)$ & $7(7.7 \%)$ & & $7(2.4)$ \\
\hline Clinical T stage, $\mathrm{n}(\%)$ & & & $<0.001^{*}$ & \\
\hline 1 & $101(51.3 \%)$ & $8(8.8 \%)$ & & $109(37.8)$ \\
\hline 2 & $72(36.5 \%)$ & $22(24.2 \%)$ & & $94(32.6)$ \\
\hline 3 & $10(5.1 \%)$ & $39(42.9 \%)$ & & $49(17.0)$ \\
\hline 4 & $2(1.0 \%)$ & $9(9.9 \%)$ & & $11(3.8)$ \\
\hline 5 & $9(4.6 \%)$ & $7(7.7 \%)$ & & $16(5.5)$ \\
\hline 6 & $0(0 \%)$ & $1(1.1 \%)$ & & $1(0.3)$ \\
\hline 7 & 0 & 0 & & 0 \\
\hline 8 & $3(15.2 \%)$ & $5(5.5 \%)$ & & $8(3.0)$ \\
\hline TNM stage, n (\%) & & & $<0.001^{*}$ & \\
\hline 1 & $169(85.8 \%)$ & $30(33.0 \%)$ & & $199(69.1)$ \\
\hline 2 & $13(6.6 \%)$ & $40(44.0 \%)$ & & $53(18.4)$ \\
\hline 3 & $12(6.1 \%)$ & $14(15.4 \%)$ & & $26(9.0)$ \\
\hline 4 & $3(1.5 \%)$ & $7(7.6 \%)$ & & $10(3.5)$ \\
\hline Surgical modality, n (\%) & & & $<0.001^{*}$ & \\
\hline Partial nephrectomy & $111(56.3 \%)$ & $14(15.4 \%)$ & & $125(43.4)$ \\
\hline Radical nephrectomy & $86(43.7 \%)$ & $77(84.6 \%)$ & & $163(56.6)$ \\
\hline Total R.E.N.A.L scores & $6.98 \pm 1.55$ & $9.56 \pm 1.41$ & $<0.001^{*}$ & \\
\hline
\end{tabular}

${ }^{*} P<0.05$

${ }^{1} \mathrm{MD} \pm \mathrm{SD}$, range

${ }^{2}$ Nearness of the tumor to the collecting system or sinus; ERLN, enlargement of lymph node. 

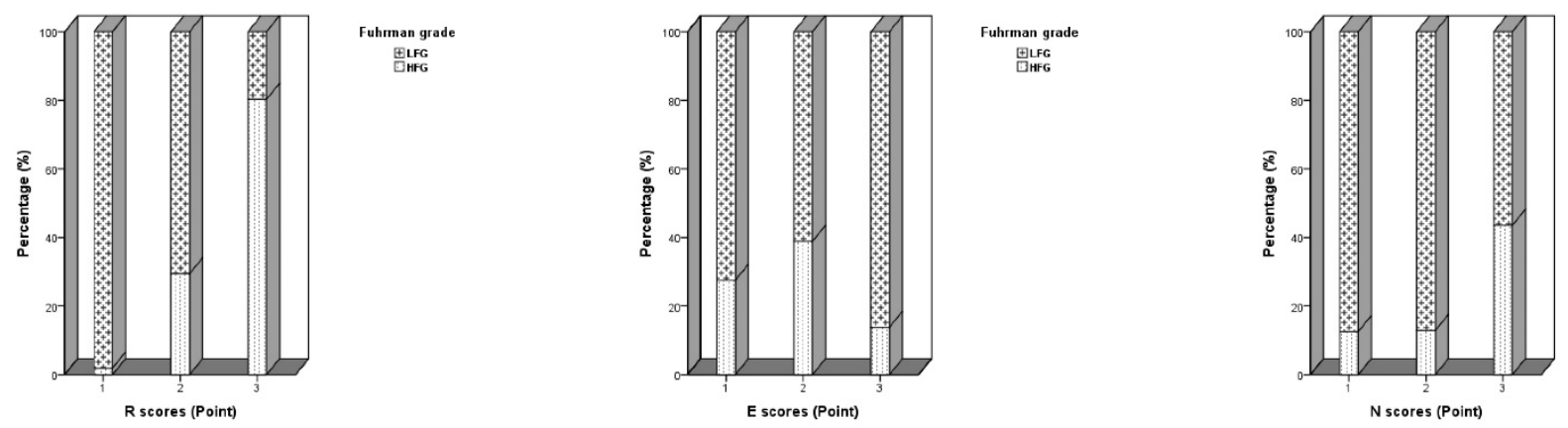

Fuhrman grade

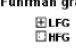

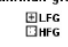

思㙕化
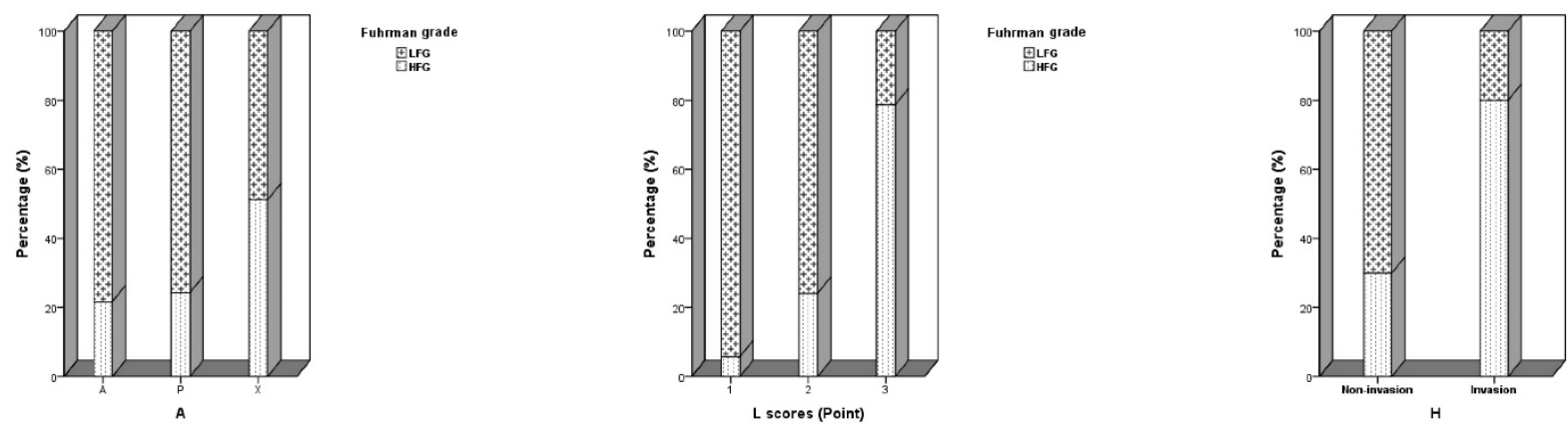

Figure 1. Distribution of individual anatomic descriptor components of the Nephrometry Score and renal hilar invasion in clear-cell renal carcinoma patients.

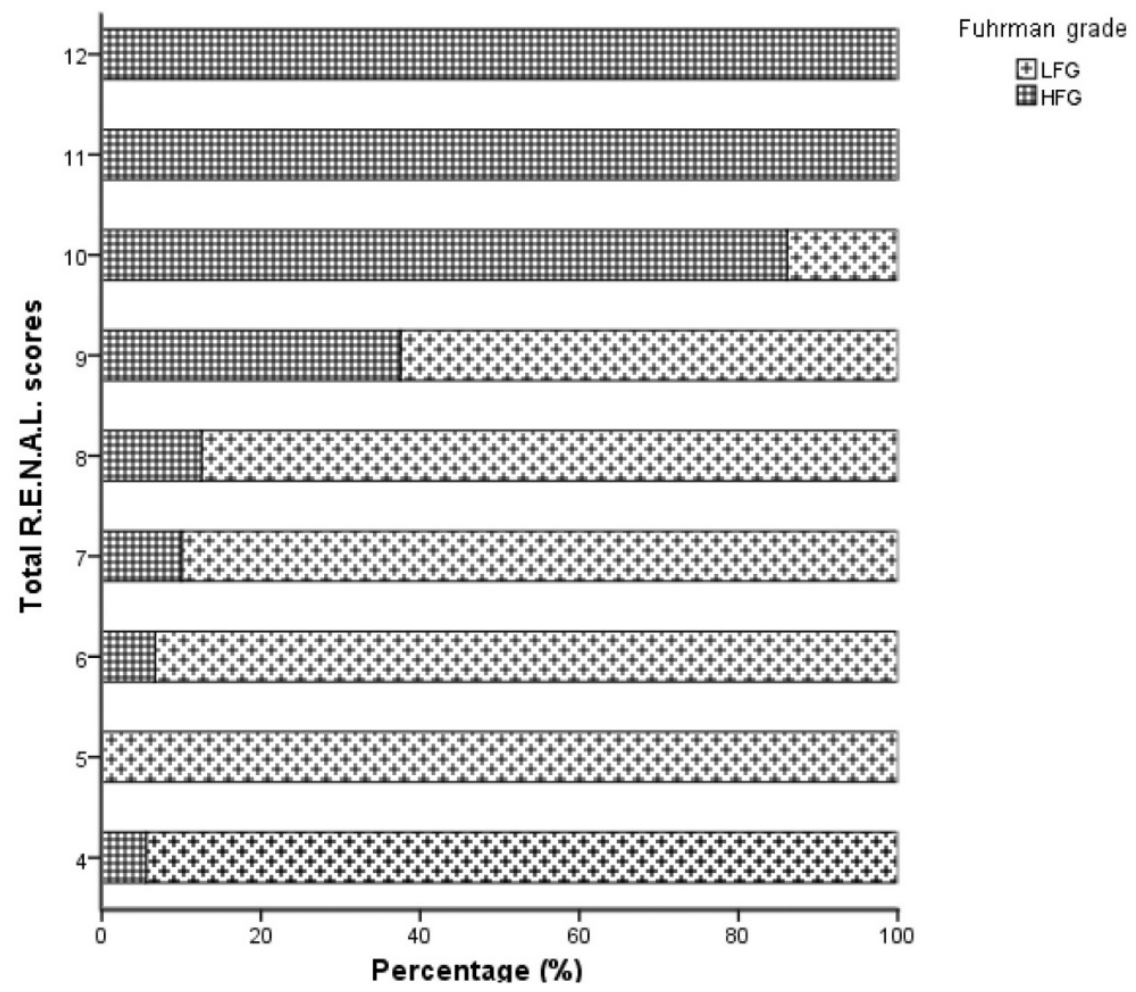

Figure 2. Distribution of the total R.E.N.A.L. Nephrometry Score of clear-cell renal carcinoma patients.

Next, ROC curves were constructed, and the areas under the ROC (AUC) with respect to the multi parameter regression model $(0.935,95 \% \mathrm{CI}$ : 0.904-0.966), tumor size (0.901, 95\% CI: 0.866-0.937), $\mathrm{R}$ score $(0.868$, 95\% CI: 0.825-0.911), E score (0.511,
95\% CI: $0.442-0.581)$ and L score $(0.842,95 \% \mathrm{CI}$ : 0.791-0.892) were calculated and compared (Table 5). This showed that the multivariable models are of a practical significance in predicting HFG based on the shape of the ROC curves and the AUC. 
Table 2. Association between tumor anatomic attributes assessed by Nephrometry score and Fuhrman grade.

\begin{tabular}{|c|c|c|c|c|}
\hline \multicolumn{2}{|c|}{ Variable } & \multicolumn{2}{|l|}{$\mathrm{N},(\%)$} & P value \\
\hline $\mathrm{R}$ & 1 & $\begin{array}{l}\text { LFG } \\
106(53.8 \%)\end{array}$ & $\begin{array}{l}\text { HFG } \\
2(2.2 \%)\end{array}$ & $<0.001^{*}$ \\
\hline \multirow[t]{2}{*}{ scores } & 2 & $77(39.1 \%)$ & $32(35.2 \%)$ & \\
\hline & 3 & $14(7.1 \%)$ & $57(62.6 \%)$ & \\
\hline $\mathrm{E}$ & 1 & $87(44.2 \%)$ & $33(36.3 \%)$ & $0.013^{*}$ \\
\hline \multirow[t]{2}{*}{ scores } & 2 & $85(43.1 \%)$ & $54(27.4 \%)$ & \\
\hline & 3 & $25(12.7 \%)$ & $4(4.3 \%)$ & \\
\hline $\mathrm{N}$ & 1 & $63(45.7 \%)$ & $9(35.1 \%)$ & $<0.001^{*}$ \\
\hline \multirow[t]{2}{*}{ scores } & 2 & $34(25.7 \%)$ & $5(30.3 \%)$ & \\
\hline & 3 & $100(28.6 \%)$ & $77(34.6 \%)$ & \\
\hline \multirow[t]{3}{*}{ A } & A & $76(38.6 \%)$ & $21(23.1 \%)$ & $<0.001^{*}$ \\
\hline & $\mathrm{P}$ & $78(39.6 \%)$ & $25(27.5 \%)$ & \\
\hline & $X$ & $43(21.8 \%)$ & $45(49.4 \%)$ & \\
\hline L & 1 & $99(50.3 \%)$ & $6(6.6 \%)$ & $<0.001^{*}$ \\
\hline \multirow[t]{2}{*}{ scores } & 2 & $82(41.6 \%)$ & $26(28.6 \%)$ & \\
\hline & 3 & $16(8.1 \%)$ & $59(64.8 \%)$ & \\
\hline \multirow[t]{2}{*}{$\mathrm{H}$} & No & $195(99.0 \%)$ & $83(91.2 \%)$ & $0.003^{*}$ \\
\hline & Yes & $2(1.0 \%)$ & $8(8.8 \%)$ & \\
\hline
\end{tabular}

${ }^{*} \mathrm{P}<0.05$; $\mathrm{R}$, radius; $\mathrm{E}$, exophytic/endophytic properties; $\mathrm{N}$, nearness of the tumor to the collecting system or sinus; A, anterior/posterior; L, location relative to the polar lines; $\mathrm{H}$, renal hilar invasion

Table 3. Multivariate Logistic regression analysis for prognostic factors of Fuhrman grade.

\begin{tabular}{ll}
\hline Factor & P value \\
\hline Symptom & 0.202 \\
Cystic necrosis & 0.332 \\
Enlargement of regional lymph node & 0.950 \\
Distant metastasis & 0.186 \\
Tumor size (cm) & $0.03^{*}$ \\
Nearness of the tumor to the collecting system or & 0.242 \\
sinus (mm) & \\
R score & $0.012^{*}$ \\
E score & $0.001^{*}$ \\
N score (1 point) & 0.259 \\
N score (2 points) & 0.226 \\
N score (3 points) & 0.871 \\
A & 0.956 \\
P & 0.781 \\
X & 0.963 \\
L score & $<0.001^{*}$ \\
H & 0.608 \\
Total R.E.N.A.L scores & 0.682 \\
Clinical T stage & 0.405 \\
TNM stage & 0.908 \\
\hline
\end{tabular}

${ }^{*} \mathrm{P}<0.05 ; \mathrm{R}$, radius; $\mathrm{E}$, exophytic/endophytic properties; $\mathrm{N}$, nearness of the tumor to the collecting system or sinus; A, anterior; $\mathrm{P}$, posterior; $\mathrm{X}$, unknown $\mathrm{A}$ or $\mathrm{P} ; \mathrm{L}$, location relative to the polar lines; $\mathrm{H}$, renal hilar invasion

\section{Discussion}

Radiographic imaging represents the cornerstone of pre-surgical diagnosis. However, it is difficult to preoperatively predict pathological grade via image testing. In nearly $70 \%-80 \%$ of renal mass biopsies the grading was well defined; however, the rate of consistency between histological biopsies and postoperative findings can be lower than $46 \%$ for pathological grade [14, 15]. Wunderlich [16] et al. reported that $15 \%$ of cases could not be correctly graded according to the final pathological results. The rates of biopsies that underestimated the nuclear grade were higher than 55\% [17]. Additionally, rare complications often accompany solid renal mass biopsies, such as pneumothorax and bleeding. Furthermore, biopsies may facilitate tumor seeding along the needle tract [18]. Tumor grading is of vital importance for therapeutic decisions and prognostic evaluations [19]. Thus, it is difficult to find an effective model to preoperatively predict the pathological grade of renal masses.

Whether the R.E.N.A.L. Nephrometry scoring system can predict malignant and high pathological grade small renal masses remains controversial. Osawa et al. [20] demonstrated that although R.E.N.A.L. Nephrometry Scores were useful for discriminating benign versus malignant renal tumors and low- versus high-grade renal masses, they were outperformed by renal mass biopsy. Furthermore, Antonelli et al. [21] showed that R.E.N.A.L. Nephrometry Scores cannot accurately predict malignancy or the aggressiveness of renal masses; the estimated area under the ROC curve for high-grade prediction was 0.57. Decision curve analysis also confirmed a poor clinical benefit for using R.E.N.A.L. Nephrometry Scores to predict aggressiveness. However, Kutikov et al. [12] revealed that Nephrometry Scores could be used to quantitate the preoperative likelihood of malignant and high histological grade renal masses, and Wang et al. [22] demonstrated that R.E.N.A.L. Nephrometry Scores could be used to predict high-grade renal cell carcinoma. The predictive value of Nephrometry Scores to discriminate high-grade renal cell carcinoma was also confirmed in an independent cohort.

This study demonstrates that there is a relationship between preoperative radiographic features and final pathological outcomes [23-25]. The individual anatomic descriptor components of Nephrometry Score and pathological grade of ccRCC were analyzed. This demonstrated that the largest tumor diameter, radius, exophytic/endophytic properties, and the location relative to the polar lines were independent prognostic factors for postoperatively predicting HFG.

This study demonstrated that larger tumor size was associated with a higher possibility of higher postoperative pathological grade. Multivariable logistic regression analysis indicated that the largest tumor diameter was an independent predictive factor for ccRCC pathological grade. Jeldres et al. [26] used data from 11 European tertiary care centers and determined that $91.5 \%$ of patients with renal masses 2 $\mathrm{cm}$ or less did not have HFG components. Frank et al. [27] demonstrated similar outcomes from the Mayo clinic, reporting that $90.8 \%$ of patients with small 
renal masses (2 $\mathrm{cm}$ or less) did not have HFG elements. It has been shown that as tumor size increases, there is a significantly greater probability of high- versus low-grade disease [28-30]. This study also demonstrated that larger tumor size was associated with a higher possibility of higher postoperative pathological grade. Multivariable logistic regression analysis indicated that the largest tumor diameter was an independent predictive factor for ccRCC pathological grade.

Table 4. Logistic regression analysis for the relationship between the anatomic descriptor components of the Nephrometry score and Fuhrman grade.

\begin{tabular}{|c|c|c|c|c|}
\hline Factor & B value & $P$ value & OR & $95 \% \mathrm{CI}$ \\
\hline Tumor size $(\mathrm{cm})$ & 0.417 & $0.03^{*}$ & 1.51 & $1.04-2.21$ \\
\hline R score (1 point) & & reference & reference & \\
\hline R score (2 points) & 2.450 & $0.008^{*}$ & 11.59 & $1.87-71.87$ \\
\hline R score ( 3 points) & 2.865 & $0.032^{*}$ & 17.56 & $1.29-239.77$ \\
\hline E score (1 point) & & reference & reference & \\
\hline E score (2 points) & 1.629 & $0.001^{*}$ & 5.10 & $2.01-12.94$ \\
\hline E score (3 points) & 1.787 & 0.081 & 5.97 & $0.80-44.53$ \\
\hline L score (1 point) & & reference & reference & \\
\hline L score (2 points) & 0.692 & 0.223 & 1.99 & $0.66-6.08$ \\
\hline L score (3 points) & 3.290 & $<0.001^{*}$ & 26.85 & $7.38-97.70$ \\
\hline Constant & -7.705 & $<0.001^{*}$ & $<0.001$ & \\
\hline
\end{tabular}

${ }^{*} \mathrm{P}<0.05 ; \mathrm{R}$, radius; $\mathrm{E}$, exophytic/endophytic properties; $\mathrm{L}$, location relative to the polar lines.

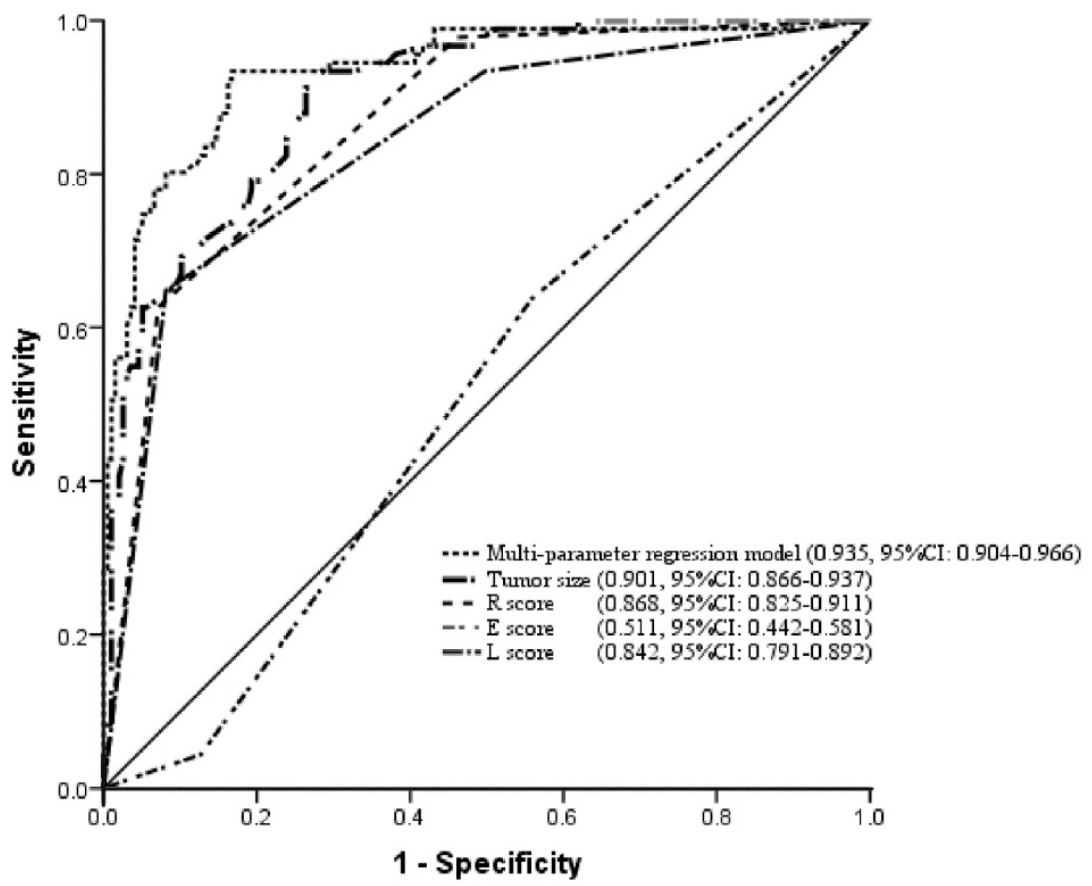

Figure 3. ROC curves were constructed using a multi-parameter regression model, $\mathrm{R}$ score, tumor size, $\mathrm{E}$ score and $\mathrm{L}$ score.

Table 5. The areas under the ROC curve with respect to multi parameter regression model, maximal diameter, radius, exophytic/endophytic properties, and location relative to the polar line were calculated and compared.

\begin{tabular}{lllll}
\hline Variable & AUC & SD & P value & $95 \%$ CI \\
\hline Model & 0.935 & 0.016 & $<0.001^{*}$ & $0.904-0.966$ \\
$\begin{array}{l}\text { Tumor size } \\
(\mathrm{cm})\end{array}$ & 0.901 & 0.018 & $<0.001^{*}$ & $0.866-0.937$ \\
R score & 0.868 & 0.022 & 0.757 & $0.825-0.911$ \\
E score & 0.511 & 0.035 & $<0.001^{*}$ & $0.442-0.581$ \\
L score & 0.842 & 0.026 & $<0.001^{*}$ & $0.791-0.892$ \\
\hline
\end{tabular}

E and L scores were also independent predictive factors for high-grade disease. Among ccRCCs with exophytic/endophytic properties below 50\%, endophytic tumors tended to be classified as HFG, while exophytic tumors tended to be classified as LFG. In this study, L score equals to 3 points was more likely to be classified as HFG than those that scored 1 point, which indicated that location relative to the polar lines was associated with higher pathological grade. Some studies have revealed a 
strong relationship between R.E.N.A.L. Nephrometry Scores and high-grade features. For example, Kutikov et al. [12] compared individual components of the R.E.N.A.L. Nephrometry Score with grade in 525 resected tumors. Consistent with our study, their results demonstrated that $\mathrm{R}$ score $(p<0.0001)$, E score $(p=0.041)$ and L score $(p=0.002)$ were strongly associated with high-grade histology. Venkatesh et al. [24] demonstrated that the fraction of tumors with high Fuhrman grades was only $3.7 \%$ among exophytic malignancies compared with $25 \%$ of endophytic renal masses, while $96 \%$ of highly exophytic malignant tumors were low-grade carcinomas. Shim et al. [31] demonstrated that hilar location, which is defined as abutting the main renal artery and/or vein or its segmental branches, was associated with higher grade renal masses compared with non-hilar location. Previous studies $[12,23,31]$ have indicated that the location of renal masses is associated with histological subtype. It has also been reported that a high percentage of endophytic tumors were of clear cell histology $[32,33]$.

The mechanisms of how $\mathrm{E}$ and $\mathrm{L}$ scores are related to high Fuhrman grades have not been elucidated. Tumors that invaded the collecting system were associated with higher Fuhrman grade and reduced survival, which has been validated by previous studies. The renal sinus and collection systems are more likely to be invaded by renal tumors, which leads to L scores of 3 points [23, 32]. The renal sinus is composed of numerous small thin-walled venous channels and lymphatics, and there is no capsule separating the renal parenchyma from the renal sinus. We hypothesize that higher $\mathrm{E}$ and L scores are more likely to be observed in high grade tumors that involve the renal sinus and exhibit venous invasion. The abundant blood supply and oxygen may facilitate tumor colonization and growth, which may contribute to tumor aggressiveness [34]. This may be a potential mechanism of how higher $\mathrm{E}$ and $\mathrm{L}$ scores correlate with high-grade renal tumors.

Overall, this study uncovered that the accuracy of prediction was 0.935 using multivariable logistic regression via ROC curves, which indicated that larger tumor size, location relative to the polar lines and endophytic tumors were more likely to be classified as HFG. This is of great practical importance for preoperatively predicting ccRCC grade. Using these data, the R.E.N.A.L. Nephrometry Score was developed with the aim of predicting the Fuhrman grade of ccRCC before intervention. R.E.N.A.L. Nephrometry Scores can accurately discriminate patients with high or low Fuhrman grades, which will help urologists choose appropriate therapies for patients.

\section{Conclusion}

This study demonstrated that larger tumors, location relative to the polar lines and endophytic tumors were more likely to be classified as higher Fuhrman grade. The R.E.N.A.L. Nephrometry Score represents a novel tool that can help urologists preoperatively predict the Fuhrman grade of renal masses and make therapeutic decisions. However, well designed randomized controlled trials are needed to make comparable results.

\section{Competing Interests}

The authors have declared that no competing interest exists.

\section{References}

1. Erdogan F, Demirel A, Polat O. Prognostic significance of morphologic parameters in renal cell carcinoma. Int J Clin Pract. 2004; 58: 333-6.

2. Ghavamian R, Cheville JC, Lohse CM, Weaver AL, Zincke H, Blute ML. Renal cell carcinoma in the solitary kidney: an analysis of complications and outcome after nephron sparing surgery. J Urol. 2002; 168: 454-9.

3. Zhang ZL, Chen W, Li YH, Liu ZW, Luo JH, Lau W, et al. Stage T1N0M0 renal cell carcinoma: the prognosis in Asian patients. Chin J Cancer. 2011; 30: 772-8.

4. Scosyrev E, Messing EM, Sylvester R, Campbell S, Van Poppel H. Renal function after nephron-sparing surgery versus radical nephrectomy: results from EORTC randomized trial 30904. Eur Urol. 2014; 65: 372-7.

5. Mouracade P, Kara O, Dagenais J, Maurice MJ, Nelson RJ, Malkoc E, et al. Perioperative morbidity, oncological outcomes and predictors of pT3a upstaging for patients undergoing partial nephrectomy for cT1 tumors. World J Urol. 2017

6. Van Poppel H, Da Pozzo L, Albrecht W, Matveev V, Bono A, Borkowski A, et al. A prospective, randomised EORTC intergroup phase 3 study comparing the oncologic outcome of elective nephron-sparing surgery and radical nephrectomy for low-stage renal cell carcinoma. Eur Urol. 2011; 59: 543-52.

7. Leibovich BC, Blute M, Cheville JC, Lohse CM, Weaver AL, Zincke H. Nephron sparing surgery for appropriately selected renal cell carcinoma between 4 and $7 \mathrm{~cm}$ results in outcome similar to radical nephrectomy. J Urol. 2004; 171: 1066-70.

8. Larcher A, Capitanio U, Terrone C, Volpe A, De Angelis P, Deho F, et al. Elective Nephron Sparing Surgery Decreases Other Cause Mortality Relative to Radical Nephrectomy Only in Specific Subgroups of Patients with Renal Cell Carcinoma. J Urol. 2016; 196: 1008-13.

9. Brookman-May S, May M, Shariat SF, Xylinas E, Stief C, Zigeuner R, et al. Features associated with recurrence beyond 5 years after nephrectomy and nephron-sparing surgery for renal cell carcinoma: development and internal validation of a risk model (PRELANE score) to predict late recurrence based on a large multicenter database (CORONA/SATURN Project). Eur Urol. 2013; 64: 472-7.

10. Mir MC, Derweesh I, Porpiglia F, Zargar H, Mottrie A, Autorino R. Partial Nephrectomy Versus Radical Nephrectomy for Clinical T1b and T2 Renal Tumors: A Systematic Review and Meta-analysis of Comparative Studies. Eur Urol. 2017; 71: 606-17.

11. Kutikov A, Uzzo RG. The R.E.N.A.L. nephrometry score: a comprehensive standardized system for quantitating renal tumor size, location and depth. J Urol. 2009; 182: 844-53.

12. Kutikov A, Smaldone MC, Egleston BL, Manley BJ, Canter DJ, Simhan J, et al. Anatomic features of enhancing renal masses predict malignant and high-grade pathology: a preoperative nomogram using the RENAL Nephrometry score. Eur Urol. 2011; 60: 241-8.

13. Wu YP, Lin TT, Chen SH, Xu N, Wei Y, Huang JB, et al. Comparison of the efficacy and feasibility of en bloc transurethral resection of bladder tumor versus conventional transurethral resection of bladder tumor: A meta-analysis. Medicine (Baltimore). 2016; 95: e5372.

14. Lebret T, Poulain JE, Molinie V, Herve JM, Denoux Y, Guth A, et al. Percutaneous core biopsy for renal masses: indications, accuracy and results. J Urol. 2007; 178: 1184-8; discussion 8.

15. Lane BR, Samplaski MK, Herts BR, Zhou M, Novick AC, Campbell SC. Renal mass biopsy--a renaissance? J Urol. 2008; 179: 20-7.

16. Wunderlich H, Hindermann W, Al Mustafa AM, Reichelt O, Junker K, Schubert J. The accuracy of 250 fine needle biopsies of renal tumors. J Urol. 2005; 174: 44-6.

17. Blumenfeld AJ, Guru K, Fuchs GJ, Kim HL. Percutaneous biopsy of renal cell carcinoma underestimates nuclear grade. Urology. 2010; 76: 610-3.

18. Stav K, Lindner A, Zisman A. Percutaneous diagnostic biopsy of solid renal masses in adults. Harefuah. 2006; 145: 164-5. 
19. Tsui KH, Shvarts O, Smith RB, Figlin R, de Kernion JB, Belldegrun A. Renal cell carcinoma: prognostic significance of incidentally detected tumors. J Urol. 2000; 163: 426-30.

20. Osawa T, Hafez KS, Miller DC, Montgomery JS, Morgan TM, Palapattu GS, et al. Comparison of Percutaneous Renal Mass Biopsy and R.E.N.A.L. Nephrometry Score Nomograms for Determining Benign Vs Malignant Disease and Low-risk Vs High-risk Renal Tumors. Urology. 2016; 96: 87-92.

21. Antonelli A, Furlan M, Sandri M, Minervini A, Cindolo L, Parma P, et al. The R.E.N.A.L. nephrometric nomogram cannot accurately predict malignancy or aggressiveness of small renal masses amenable to partial nephrectomy. Clin Genitourin Cancer. 2014; 12: 366-72.

22. Wang HK, Zhu Y, Yao XD, Zhang SL, Dai B, Zhang HL, et al. External validation of a nomogram using RENAL nephrometry score to predict high grade renal cell carcinoma. J Urol. 2012; 187: 1555-60.

23. Schachter LR, Bach AM, Snyder ME, Kattan MW, Russo P. The impact of tumour location on the histological subtype of renal cortical tumours. BJU Int. 2006; 98: 63-6.

24. Venkatesh R, Weld K, Ames CD, Figenshau SR, Sundaram CP, Andriole GL, et al. Laparoscopic partial nephrectomy for renal masses: effect of tumor location. Urology. 2006; 67: 1169-74; discussion 74.

25. Weizer AZ, Gilbert SM, Roberts WW, Hollenbeck BK, Wolf JS, Jr. Tailoring technique of laparoscopic partial nephrectomy to tumor characteristics. J Urol. 2008; 180: 1273-8.

26. Jeldres C, Sun M, Liberman D, Lughezzani G, de la Taille A, Tostain J, et al. Can renal mass biopsy assessment of tumor grade be safely substituted for by a predictive model? J Urol. 2009; 182: 2585-9.

27. Frank I, Blute ML, Cheville JC, Lohse CM, Weaver AL, Zincke H. Solid renal tumors: an analysis of pathological features related to tumor size. J Urol. 2003; 170: 2217-20.

28. Tsivian M, Mouraviev V, Albala DM, Caso JR, Robertson CN, Madden JF, et al. Clinical predictors of renal mass pathological features. BJU Int. 2011; 107: 735-40.

29. Rothman J, Egleston B, Wong YN, Iffrig K, Lebovitch S, Uzzo RG. Histopathological characteristics of localized renal cell carcinoma correlate with tumor size: a SEER analysis. J Urol. 2009; 181: 29-33; discussion -4.

30. Thompson RH, Hill JR, Babayev Y, Cronin A, Kaag M, Kundu S, et al. Metastatic renal cell carcinoma risk according to tumor size. J Urol. 2009; 182: 41-5.

31. Shim M, Song C, Park S, Kim A, Choi SK, Kim CS, et al. Hilar location is an independent prognostic factor for recurrence in T1 renal cell carcinoma after nephrectomy. Ann Surg Oncol. 2015; 22: 344-50.

32. Chen L, Li H, Gu L, Ma X, Li X, Zhang F, et al. Prognostic role of urinary collecting system invasion in renal cell carcinoma: a systematic review and meta-analysis. Sci Rep. 2016; 6: 21325.

33. Uzzo RG, Cherullo E, Myles J, Novick AC. Renal cell carcinoma invading the urinary collecting system: implications for staging. J Urol. 2002; 167: 2392-6.

34. Hayes BD, Finn SP. Kidney volume correlates with tumor diameter in renal cell carcinoma and is associated with histological poor prognostic features. Int J Surg Pathol. 2014; 22: 39-46. 